\title{
Crescimento de Raízes dos Capins Aruana e Tanzânia Submetidos a Duas Doses de Nitrogênio ${ }^{1}$
}

\section{Alessandra Aparecida Giacomini ${ }^{2}$, Waldssimiler Teixeira de Mattos ${ }^{3}$, Herbert Barbosa de Mattos $^{4}$, Joaquim Carlos Werner ${ }^{4}$, Eduardo Antonio da Cunha ${ }^{4}$, Dora Duarte de Carvalho ${ }^{4}$}

RESUMO - Foram avaliadas características do sistema radicular (pré e pós-pastejo) dos capins aruana e tanzânia submetidos a doses de nitrogênio ( 150 e $300 \mathrm{~kg} \mathrm{ha}^{-1}$ de N) e pastejados por ovinos em lotação rotacionada com três a sete dias de pastejo e período de descanso variável. O delineamento experimental foi o de blocos completos casualizados (dois) com duas repetições, em esquema de parcelas subdivididas (parcelas =capins e subparcelas=doses de N) e medidas repetidas no tempo. No pré-pastejo, o capim-tanzânia, na média entre doses de $\mathrm{N}$ e períodos de pastejo, apresentou maior quantidade de massa seca da matéria orgânica (MSMO) $\left(1,7 \mathrm{mg} \mathrm{cm}^{-3}\right.$ de solo)

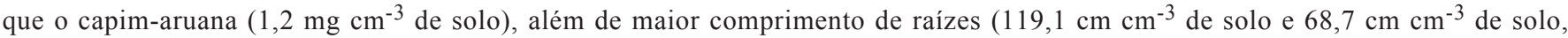
respectivamente). A dose de $300 \mathrm{~kg} \mathrm{ha}^{-1} \mathrm{de} \mathrm{N}$ contribuiu para maior comprimento do sistema radicular $\left(107,1 \mathrm{~cm} \mathrm{~cm}^{-3}\right.$ de solo) que a dose de $150 \mathrm{~kg} \mathrm{ha}^{-1}$ de $\mathrm{N}\left(80,7 \mathrm{~cm} \mathrm{~cm}^{-3}\right.$ de solo). O crescimento radicular pós-pastejo demonstrou similaridade de comportamento entre as variáveis mensuradas, de modo que o crescimento de raízes se tornou mais evidente após a segunda semana de rebrotação. Na média de capins, doses de $\mathrm{N}$ e idades de crescimento, no período equivalente ao outono/inverno, o crescimento de raízes (em MSMO foi de $3,9 \mathrm{mg} 100 \mathrm{~cm}^{-3}$ ) aumentou para $12,9 \mathrm{mg} 100 \mathrm{~cm}^{-3}$ no inverno, caiu para $4,7 \mathrm{mg} 100 \mathrm{~cm}^{-3}$ na primavera e elevou novamente para $17 \mathrm{mg}$ $100 \mathrm{~cm}^{-3}$ no verão. Comportamento semelhante foi observado para comprimento e superfície de raízes, coincidindo os períodos de maior crescimento com os de maior pluviosidade. A dose de $150 \mathrm{~kg} \mathrm{ha}^{-1} \mathrm{de} \mathrm{N}$ promoveu maior crescimento em comprimento e superfície de raízes que a dose de $300 \mathrm{~kg} \mathrm{ha}^{-1}$ de $\mathrm{N}$ nos períodos de maior pluviosidade.

Palavras-chave: fertilização nitrogenada, Panicum maximum, sistema radicular

\section{Root Mass and Growth from Aruanagrass and Tanzaniagrass under Nitrogen Rates}

ABSTRACT - The root system (pre and post grazing) characteristics of aruanagrass and tanzaniagrass under two nitrogen rates (150 and $300 \mathrm{~kg} \mathrm{ha}^{-1} \mathrm{~N}$ year) grazed by sheep in variable rotational stocking (three to seven grazing days) and variable rest period were evaluated in this study. The treatments were assigned to a complete randomized block (two) design with two replicates (plots = grasses and splitplots $=$ nitrogen rates)within repeated measures. In the pre-grazing tanzaniagrass, averages within nitrogen rates and grazing period showed higher amount of dry matter of organic matter (DMOM) $\left(1.7 \mathrm{mg} \mathrm{cm}^{-3}\right.$ of soil) than aruanagrass $\left(1.2 \mathrm{mg} \mathrm{cm}^{-3}\right.$ of soil $)$ and greater root length $\left(119.1 \mathrm{~cm} \mathrm{~cm}^{-3}\right.$ of soil $\mathrm{x} 68.7 \mathrm{~cm} \mathrm{~cm}^{-3}$ of soil). The $300 \mathrm{~kg} \mathrm{ha}^{-1} \mathrm{~N}$ rate contributed to a higher root system length $\left(107.1 \mathrm{~cm} \mathrm{~cm}^{-3} \mathrm{of}\right.$ soil) than the $150 \mathrm{~kg} \mathrm{ha}^{-1} \mathrm{~N}$ rate $\left(80.7 \mathrm{~cm} \mathrm{~cm}^{-3}\right.$ of soil). Post-grazing root growth showed similar behavior among the variables measured and was more evident after the second regrowth week. Considering averages within grasses, nitrogen rates and growth age, in the period equivalent to Autumn/Winter, the DMOM growth root was of $3.9 \mathrm{mg} 100 \mathrm{~cm}^{-3}$, increased by $12.9 \mathrm{mg} 100 \mathrm{~cm}^{-3}$ in Winter, decreased by $4.7 \mathrm{mg} 100 \mathrm{~cm}^{-3}$ from Winter to Spring, and increased by $17 \mathrm{mg} 100 \mathrm{~cm}^{-3}$ on Summer. Similar behavior for both root length and surface

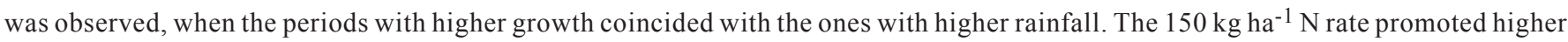
length and surface than the $300 \mathrm{~kg} \mathrm{ha}^{-1} \mathrm{~N}$ in the periods with higher rainfall.

Key Words: nitrogen fertilization, Panicum maximum, root system

\section{Introdução}

Tendo em vista a importância econômica da produção de ovinos em pastagens, são de extrema relevância medidas acertadas no manejo, incluindo a adubação, visando aumentar sua produtividade e lucratividade. Além disso, tem-se verificado crescen- te preocupação de técnicos e produtores por sistemas intensivos de pastejo para ovinos, com interesse em cuidados com o manejo da pastagem, a manutenção e reposição da fertilidade do solo. Todavia, são poucas são as informações na literatura sobre manejo de pastagens de cultivares de Panicum maximum Jacq. para ovinos.

\footnotetext{
${ }^{1}$ Parte da dissertação da primeira autora. Projeto financiado pela FAPESP.

2 Estudante do curso de Doutorado em Ciência Animal e Pastagens, ESALQ-USP.E.mail: alegiacomini@hotmail.com

3 Pesquisador do Instituto de Zootecnia, Nova Odessa/SP e ex-bolsista de pós-doutorado da FAPESP.

4 Pesquisador Aposentado do Instituto de Zootecnia, Nova Odessa/SP, CP 60, CEP: 13460-000.

5 Pesquisador do Instituto de Zootecnia, Nova Odessa/SP, CP 60, CEP: 13460-000.
} 
Para a lotação intermitente com ovinos, a utilização de capins do gênero Panicum seria uma alternativa interessante, em razão de sua elevada capacidade de produção de forragem por unidade de área e hábito de crescimento cespitoso. O manejo proposto em capins de hábito de crescimento cespitoso para ovinos, com rebaixamento acentuado da forragem (15 - $20 \mathrm{~cm}$ de altura), é recomendado para reduzir a infestação da pastagem por larvas de helmintos. Com manejo baixo, há redução significativa no número de larvas infestantes pela exposição à radiação ultravioleta, maior ventilação e temperatura elevada nos estratos inferiores (Santos et al., 2001).

A produtividade da parte aérea é reflexo do que acontece com o sistema radicular, pois ambos interagem. Logo, qualquer fator que limite o crescimento de raízes pode prejudicar a produção de massa seca da planta forrageira. As informações sobre o crescimento de raízes na literatura são poucas, contrariamente àquelas disponíveis para a parte aérea. Ainda pouco se conhece sobre os mecanismos de crescimento do caule, muito menos se sabe sobre os da raiz (Scurlock \& Hall, 1998; Matta, 1999; Bono et al., 2000). Pelo conhecimento prévio do crescimento e da distribuição do sistema radicular, pode-se orientar práticas que visem aumentar a perenidade e produtividade da pastagem no sistema de produção (Da Costa et al., 1983).

O ecossistema de pastagens é dinâmico; apresenta a distribuição de sua produção anual entre as partes aérea e subterrânea, mas pode sofrer alterações decorrentes das condições de meio ambiente. Em um sistema de pastejo, a parte vegetativa aérea é mais estudada e valorizada porque é consumida pelos animais, mas a planta deve ser estudada como um todo, pois as diferentes estruturas que a compõem interagem para seu crescimento e sua produção. Embora não sejam consumidas, as raízes devem ser consideradas e estudadas em virtude de sua elevada importância na capacidade de armazenar carboidratos e proteínas, o que influencia diretamente na rebrotação após desfolhação. O pastejo afeta diretamente o crescimento do sistema radicular, influindo na capacidade das plantas forrageiras de resistir a períodos de estresse hídrico e competir por nutrientes no solo (Herling et al., 2001).

Segundo Richards (1993), estudos com plantas C3 e C4 têm mostrado que o crescimento de raízes cessa após a remoção de cerca de $50 \%$ ou mais de sua área foliar. Portanto, é inevitável a redução no crescimento do sistema radicular imediatamente após a desfolhação, proporcionalmente à frequência de corte ou pastejo. Por outro lado, esse comportamento após a desfolhação parece ser uma estratégia fisiológica da planta forrageira, que busca proporcionar rápida recuperação da parte aérea (rápida retomada do processo fotossintético) e, conseqüente equilíbrio positivo de carbono na planta por meio da diminuição da demanda de carbono pelo sistema radicular (Richards, 1993). Contudo, essa redução do crescimento de raízes também implica em menor capacidade de absorção de água e nutrientes pela planta forrageira.

A disponibilidade de água no solo afeta a taxa de elongação das raízes e a absorção dos nutrientes pelas mesmas (Singh, 1998). De acordo com Voorhees et al. (1980), a massa seca de raízes é um atributo fácil de ser obtido em relação a resultados de comprimento do sistema radicular, mas somente a massa seca de raízes não expressa a extensão em que determinado volume de solo é explorado pelo sistema radicular e, conseqüentemente, não se pode avaliar de forma consistente os processos de absorção de água e nutrientes. Nesse sentido, o comprimento das raízes pode ser uma variável importante para o estudo de crescimento da planta, contribuindo para gerar informações relacionadas à fisiologia e ao estado nutricional do vegetal.

A camada de $0-20 \mathrm{~cm}$ de solo seria a responsável pela maior proporção do volume radicular de gramíneas (Carvalho, 1999; Matthew, 1992; Bono et al., 2000). A dificuldade de coleta em maiores profundidades pode ser fator limitante para a maior parte dos estudos com raízes (Pagotto, 2001), pois, a partir de $20 \mathrm{~cm}$ de profundidade, a amostragem se torna difícil e trabalhosa. A amostragem de raízes na camada de 0-20 cm, por ser mais fácil de se realizar, dispende menor tempo, podendo-se coletar maior número de amostras, buscando diminuir a variabilidade dos dados, que é excessivamente alta para estudos com raízes (Vogt \& Bloomfield, 1991; Pagotto, 2001). Segundo Deinum (1985), a variação na medida de massa seca de raízes é normalmente grande e varia de 20 a 50\%.

Portanto, verifica-se a importância do estudo do sistema radicular, pois é um dos responsáveis pela produção e perenidade do pasto, juntamente a fatores ligados ao manejo, à adubação nitrogenada, ao solo e ao clima. Neste experimento, objetivou-se avaliar o crescimento de raízes de acordo com o manejo da pastagem e a adubação nitrogenada, visando fornecer bases para maior entendimento do comportamento da planta forrageira no sistema de produção. 


\section{Material e Métodos}

O experimento foi desenvolvido em uma área experimental pertencente ao Instituto de Zootecnia, Nova Odessa - SP (22042' latitude Sul, $47^{\circ} 18^{\prime}$ ' longitude Oeste e $528 \mathrm{~m})$. O período experimental foi de 21/05/2002 a 14/03/2003 e os dados climáticos referentes ao período foram coletados no posto meteorológico do Instituto de Zootecnia, Nova Odessa/ SP (Figura 1).

A área experimental situou-se num solo classificado como Argissolo Vermelho-Amarelo Distrófico (Empresa Brasileira de Pesquisa Agropecuária, 1999) e foi constituída de quatro piquetes com, aproximadamente, $1500 \mathrm{~m}^{2}$ cada, estabelecidos em dezembro de 2000 - dois com capim-aruana (Panicum maximum Jacq. cv. Aruana) e dois com capim-tanzânia (Panicum maximum Jacq. cv. Tanzânia), perfazendo dois blocos experimentais. De acordo as análises químicas do solo antes do experimento (Tabelas 1 e 2), não havia necessidade de calagem ou aplicação de nutrientes, exceto nitrogênio, em relação às exigências das espécies em estudo (Werner et al., 2001) e, por isso, não foi realizada prática de correção do solo.

Em cada bloco, os piquetes foram divididos com cerca eletrificada, para se aumentar o número de parcelas experimentais (repetição). Cada parcela (metade do piquete) foi considerada a repetição dentro do bloco. As quatro parcelas de cada capim foram

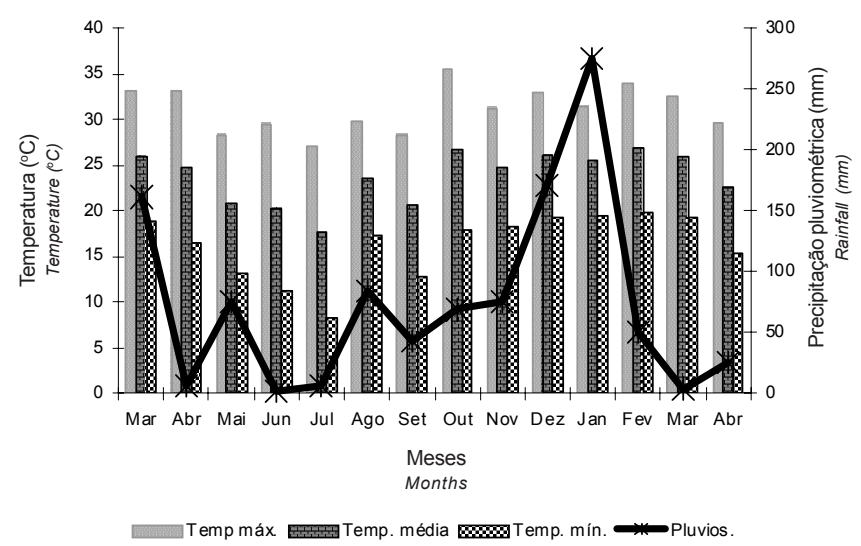

Figura 1 - Temperaturas máxima, mínima, média $\left({ }^{\circ} \mathrm{C}\right)$ e precipitação pluvial $(\mathrm{mm})$, durante o período experimental.

Figure 1 - Maximum, minimum and medium temperature $\left({ }^{\circ} \mathrm{C}\right)$ and rainfall during the experimental period. pastejadas seqüencialmente em sistema intermitente de três a sete dias de pastejo (para atingir $20 \mathrm{~cm}$ de altura do resíduo pós-pastejo em ambos os capins) por dois lotes de ovinos (mob grazing). O período de descanso foi variável. Os tratamentos utilizados foram os capins aruana e tanzânia (parcelas) e as doses de nitrogênio de 150 e $300 \mathrm{~kg} \mathrm{ha}^{-1}$ de $\mathrm{N}$, subparcelas pastejadas simultaneamente (sem separação por cercas). A aplicação de cada dose de $\mathrm{N}$ foi parcelada com $1 / 3$ no início das águas (novembro e dezembro/2003) e os outros 2/3 no final das águas (março e abril/ 2002), conforme Werner et al. (2001). Utilizou-se delineamento de blocos completos casualizados, em parcelas subdivididas, com quatro repetições e medidas repetidas no tempo. Os capins constaram das parcelas principais e o nitrogênio, das subparcelas. A análise de variância dos dados foi realizada por meio do procedimento MIXED do pacote estatístico SAS (Statistical Analysis System) (SAS, 1999) versão 8.02 para Windows. As interações significativas foram comparadas pelo teste Tukey a $10 \%$.

Foram coletadas, antes da entrada dos animais, quatro amostras de raízes de cada unidade experimental, na profundidade de zero a $20 \mathrm{~cm}$, utilizandose uma sonda de dois $\mathrm{cm}$ de diâmetro, sendo o volume de terra coletado de $62,8 \mathrm{~cm}^{3}$. Dessas amostras, foram feitas amostras compostas com volume de terra total de $251,2 \mathrm{~cm}^{3}$. A coleta foi realizada ao lado da base de touceiras representativas da área, selecionadas por meio do método da reta transecta (Carvalho et al., 2003), de maneira que representassem o tamanho médio das touceiras presentes na unidade experimental. Segundo estudo realizado na área experimental por Carvalho et al. (2003), a área de solo coberta por plantas, na média dos dois capins, foi de $47 \%$. Por isso, optou-se por não extrapolar os dados para hectare, evitando-se super estimativa de raízes, expressando os resultados das amostragens em relação $\mathrm{a}^{3}$ de solo. As datas de amostragem foram: $\mathrm{C} 1=21 / 05$ a 11/06 (outono); $\mathrm{C} 2=17 / 07$ a 07/08 (inverno); $\mathrm{C} 3=05 / 09$ a 25/ 09 (primavera); $\mathrm{C} 4=08 / 01$ a 06/02 (verão), sendo realizadas oito coletas por período.

Após a saída dos animais, foram avaliados os períodos de rebrotação, que abrangeram as seguintes datas: R1 = 30/05 a 17/07/02 (outono/inverno), R2 = 22/07 a 12/09/02 (inverno), R3 = 11/09 a 28/10/02 (primavera), e R4 $=14 / 01$ a 14/03/03 (verão). Em cada unidade experimental, foram selecionadas $\mathrm{e}$ identificadas com estacas de madeira quatro touceiras representativas da área (Carvalho et al., 2003), foram 
Tabela 1 - Resultado da análise do solo dos piquetes com o capim-aruana Table 1 - Soil analysis result from aruanagrass paddocks

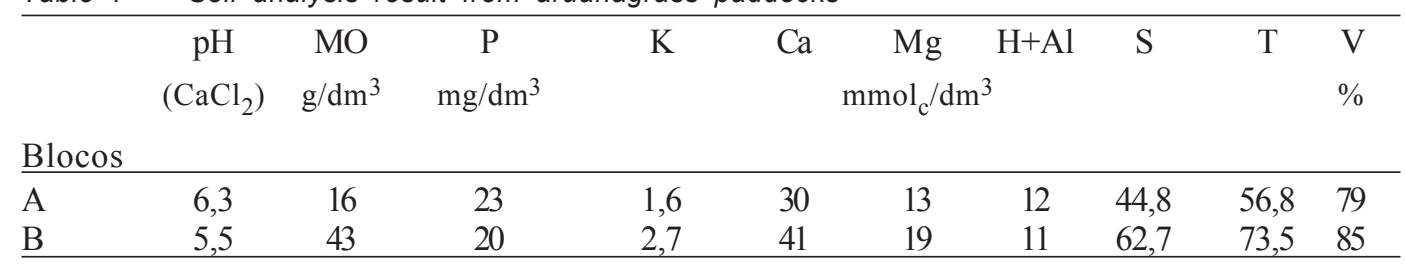

Tabela 2 - Resultado da análise de solo dos piquetes com o capim-tanzânia Table 2 - Soil analysis result from tanzaniagrass paddocks

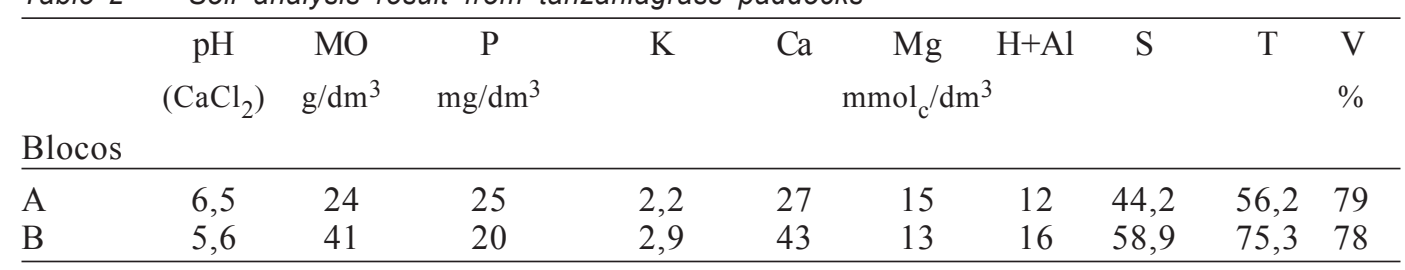

feitos dois buracos ao lado da base de cada touceira (oito buracos cilíndricos no perfil do solo por unidade experimental) com sonda de dois cm de diâmetro, na profundidade de 0 a $20 \mathrm{~cm}$. O solo foi retirado, os buracos preenchidos com areia de rio lavada e cobertos, então, com uma camada de argila de aproximadamente $15 \mathrm{~mm}$, pressionada no topo de cada buraco para agir como lacre, conforme Matthew (1992). A cada sete dias, foi sorteada uma das quatro touceiras e retirado o material contido nos dois buracos, para formar uma amostra composta com volume de $125,6 \mathrm{~cm}^{3}$.

Todo o material coletado foi lavado em água corrente, utilizando-se uma peneira de malha de 0,25 $\mathrm{mm}$, separando as raízes do solo. Após lavagem, foram feitas a limpeza e a separação das raízes, que foram acondicionadas em uma solução contendo $70 \%$ de álcool etílico, para análises posteriores.

As raízes foram retiradas do álcool e coradas em uma solução de $0,5 \%$ de azul de metileno por cinco minutos e, em seguida, foram distribuídas em bandeja de vidro de 36 x $23 \mathrm{~cm}$ e $3,5 \mathrm{~cm}$ de altura, com $150 \mathrm{~mL}$ de água, que foi colocada sobre um escâner de mesa com resolução de 300 dpi. As imagens das raízes, obtidas pela varredura efetuada pelo escâner e transferidas automaticamente para um arquivo no computador, foram consideradas imagens já digitalizadas, prontas para o processamento do cálculo do comprimento total e da superfície radicular. O comprimento total e a superfície das raízes foram estimados pelo sistema Delta T SCAN Image Analisys Software, que fornece medidas acuradas do comprimento e da superfície de raízes (Greenwood \& Hutchinson, 1998; Bouma et al., 2000) expresso em unidade por volume de solo. Seqüencialmente, as amostras de raízes foram colocadas em estufa com circulação forçada a $65^{\circ} \mathrm{C}$ até peso constante e pesadas para determinação dos teores de matéria seca. Posteriormente, foram transferidas para mufla a $650^{\circ} \mathrm{C}$, por 4 horas, para determinação da matéria mineral, necessária para o cálculo da massa da matéria orgânica (MSMO) das raízes.

$\mathrm{Na}$ avaliação de raízes pré-pastejo, foram determinados a massa seca da matéria orgânica, o comprimento e a superfície de raízes. Os valores foram expressos em $\mathrm{mg} \mathrm{cm}^{-3}, \mathrm{~cm} \mathrm{~cm}^{-3} \mathrm{e} \mathrm{cm}^{2} \mathrm{~cm}^{-3}$ de solo, respectivamente. Na avaliação do crescimento radicular pós-pastejo, os valores de MSMO, comprimento e superfície de raízes foram expressos em $\mathrm{mg} 100 \mathrm{~cm}^{-3}, \mathrm{~cm} 100$ $\mathrm{cm}^{-3} \mathrm{e} \mathrm{cm}^{2} 100 \mathrm{~cm}^{-3}$ de solo, respectivamente.

\section{Resultados e Discussão}

Para massa seca da matéria orgânica $\left(\mathrm{mg} \mathrm{cm}^{-3} \mathrm{de}\right.$ solo) de raízes, houve interação capins x doses de $\mathrm{N}$ (Tabela 3 ). O capim-tanzânia apresentou maior MSMO para a dose de 300 em relação à de $150 \mathrm{~kg} \mathrm{ha}^{-1}$ de $\mathrm{N}$, enquanto a MSMO do capim-aruana não diferiu $(\mathrm{p}>0,10)$ entre as doses de $\mathrm{N}$ estudadas.

$\mathrm{O}$ capim-tanzânia, na média entre doses de $\mathrm{N}$ e ciclos de pastejo, teve maior quantidade de MSMO $\left(1,7 \mathrm{mg} \mathrm{cm}^{-3}\right.$ de solo) que o capim-aruana $\left(1,2 \mathrm{mg} \mathrm{cm}^{-3} \mathrm{de}\right.$ solo), provavelmente em virtude de seu maior porte. Isso pôde ser observado visualmente, pois, em perío- 
Tabela 3 - Massa seca da matéria orgânica de raízes $\left(\mathrm{mg} \mathrm{cm}^{-3}\right.$ de solo) para os capins aruana e tanzânia e doses médias de N (150 e $\left.300 \mathrm{~kg} \mathrm{ha}^{-1}\right)$ dos quatro ciclos de pastejo Table 3 - Dry matter from root organic matter $\left(\mathrm{mg} \mathrm{cm}^{-3}\right.$ of soil) of aruanagrass and tanzaniagrass and $N$ rates (150 and $\left.300 \mathrm{~kg} \mathrm{ha}^{-1}\right)$, average of four grazing cycles

\begin{tabular}{lcc}
\hline & \multicolumn{2}{c}{$\begin{array}{c}\text { Dose de } \mathrm{N}\left(\mathrm{kg} \mathrm{ha}^{-1}\right) \\
\text { Nitrogen rate }\end{array}$} \\
\cline { 2 - 3 } Capim & $150 \mathrm{~kg} \mathrm{~N}$ & $300 \mathrm{~kg} \mathrm{~N}$ \\
\hline Arass & $1,2^{\mathrm{aA}}$ & $1,1^{\mathrm{bA}}$ \\
Tanzâna & $1,6^{\mathrm{aB}}$ & $1,8^{\mathrm{aA}}$ \\
\hline
\end{tabular}

\footnotetext{
${ }_{1}^{1}$ Médias na mesma coluna seguidas da mesma letra minúscula não diferem $(p>0,10)$ entre si.

${ }_{1}^{1}$ Means in the same column followed by the same small letter do not differ $(p>0.10)$.

2 Médias na mesma linha seguidas da mesma letra maiúscula não diferem $(p>0,10)$ entre si.

${ }^{2}$ Means in the same row followed by the same capital letter do not differ $(p>0.10)$.
}

dos de seca mais prolongados, o capim-tanzânia demoroou mais tempo para mostrar estresse hídrico (enrolamento de folhas).

A maior MSMO observada para a dose de $300 \mathrm{~kg} \mathrm{ha}^{-1}$ de $\mathrm{N}$ difere dos resultados obtidos por Cecato et al. (2003), que avaliaram o peso seco de raízes do capim-tanzânia adubado com quatro doses de nitrogênio $\left(50,100,200\right.$ e $400 \mathrm{~kg} \mathrm{ha}^{-1} \mathrm{de} \mathrm{N}$, fracionadas em quatro aplicações durante a primavera e verão), porém trabalhando apenas no período das águas (setembro a maio), com pastejo sob lotação contínua e taxa de lotação variável, mantendo altura média do dossel forrageiro em $50 \mathrm{~cm}$. Esses autores reportaram que a produção de MS de raízes foi semelhante entre as doses de $\mathrm{N}$ utilizadas, sendo de 51, 50, 47 e $40 \mathrm{mg}$ de raízes $/ 687 \mathrm{~cm}^{3}$ de solo para as doses de 50,100, 200 e $400 \mathrm{~kg} \mathrm{ha}^{-1}$ de $\mathrm{N}$, respectivamente, o que, segundo os autores, decorreu do manejo adequado, mantendo-se a altura média do dossel forrageiro em $50 \mathrm{~cm}$ para todos os tratamentos e elevado índice de área foliar, o que resultou em pesos semelhantes. No entanto, não foi mencionada a profundidade de coleta, apenas o volume de solo coletado. Esse fato, juntamente com a época do ano e o manejo do pastejo adotado, podem ser motivos pelos quais os valores diferiram dos encontrados neste trabalho.

A MSMO do sistema radicular diferiu $(\mathrm{P}<0,10)$ entre os ciclos de pastejo (Tabela 4). No C1 (outono), a MSMO de raízes foi menor $(\mathrm{P}<0,10)$ que nos demais ciclos avaliados que, por sua vez, não diferiram entre si $(\mathrm{P}>0,10)$. Pagotto (2001), por sua vez, avaliando o sistema radicular do capim-tanzânia irrigado, não verificou diferença entre massa de raízes pré-pastejo entre os períodos de primavera, verão e outono. Tosi (1999), avaliando o sistema radicular do capimtanzânia em pastejo, em São Carlos (SP), reportou que maior massa de raízes foi observada durante os meses de janeiro e fevereiro (verão). No período C2, houve elevada massa de raízes, diferindo do comportamento por esses autores. Mas, no período anterior a $\mathrm{C} 2$, ocorreram as menores precipitações e temperaturas (Figura 1), que causaram menor crescimento da parte aérea. Portanto, esse é um período de menor acúmulo de forragem (Giacomini, 2003), quando os compostos de reserva não estão sendo utilizados para o crescimento da parte aérea, podendo ser empregados pelo sistema radicular, favorecendo seu crescimento. Lupinacci (2002), estudando capim-marandu em lotação contínua, registrou maiores massas de raízes nos meses de setembro e outubro, explicando esse comportamento pela ausência de condições climáticas favoráveis ao crescimento da parte aérea da planta forrageira.

As variáveis comprimento (Tabela 5) e superfície (Tabela 6) das raízes no pré-pastejo apresentaram comportamento semelhante: por isso, optou-se por discuti-las simultaneamente. Ambas as variáveis diferiram $(\mathrm{P}<0,10)$ entre capins, doses de $\mathrm{N}$ e ciclos de pastejo, havendo interação capins $\mathrm{x}$ doses de $\mathrm{N}$, ciclos de pastejo $\mathrm{x}$ doses de $\mathrm{N}$, e ciclos de pastejo $\mathrm{x}$ capins $\mathrm{x}$ doses de N. O desdobramento dessa última interação foi utilizado para mostrar os resultados obtidos (Tabelas 5 e 6 ).

O comportamento dos dois capins foi diferente quanto ao comprimento e superfície do sistema radicular ao longo dos ciclos de pastejo, de modo que, para o capim-aruana, essas variáveis foram superiores no $\mathrm{C} 2$ e $\mathrm{C} 3$ (inverno e primavera), enquanto, para o capim-tanzânia, isso ocorreu no C4 (verão) (Tabelas 5 e 6), comprovando diferenças morfofisiológicas entre eles. As características em comum para ambos os capins foram menores MSMO, comprimento e superfície do sistema radicular no $\mathrm{C} 1$ (outono). 
Tabela 4 - Massa de raízes pré-pastejo $\left(\mathrm{mg} \mathrm{cm}^{-3}\right.$ de solo) em quatro ciclos de pastejo para os capins aruana e tanzânia. Média das doses de $\mathrm{N}$ e dos capins

Table 4 - Pre-grazing root mass $\left(\mathrm{mg} \mathrm{cm}^{-3}\right.$ of soil) in four grazing periods of aruanagrass and tanzaniagrass. Average of $N$ rates and grasses

\begin{tabular}{lcccc}
\hline \multicolumn{4}{c}{$\begin{array}{c}\text { Ciclo de pastejo } \\
\text { Grazing cycle }\end{array}$} \\
\cline { 2 - 5 } & $\begin{array}{c}\text { C1Outono } \\
\text { Autumn }\end{array}$ & $\begin{array}{c}\text { C2Inverno } \\
\text { Winter }\end{array}$ & $\begin{array}{c}\text { C3Primavera } \\
\text { Spring }\end{array}$ & $\begin{array}{c}\text { C4Verão } \\
\text { Summer }\end{array}$ \\
\hline Média & $1,2^{\mathrm{b}}$ & $1,6^{\mathrm{a}}$ & $1,5^{\mathrm{a}}$ & $1,5^{\mathrm{a}}$ \\
Mean & 0,09 & 0,09 & 0,09 & 0,11 \\
\hline EPM & 0,09 &
\end{tabular}

${ }_{1}^{1}$ Médias na mesma linha seguidas da mesma letra minúscula não diferem entre si $(p>0,10)$.

1 Means in the same row followed by the same small letter do not differ $(p>0.10)$.

2 EPM: erro-padrão da média.

${ }^{2}$ EPM: standard error.

Tabela 5 - Comprimento $\left(\mathrm{cm} \mathrm{cm}^{-3}\right.$ de solo) de raízes dos capins aruana e tanzânia, em quatro ciclos de pastejo e duas doses de $\mathrm{N}$

Table 5 - Root length ( $\mathrm{cm} \mathrm{cm}^{-3}$ of soil) of aruanagrass and tanzaniagrass, in four grazing cycles and two $N$ rates

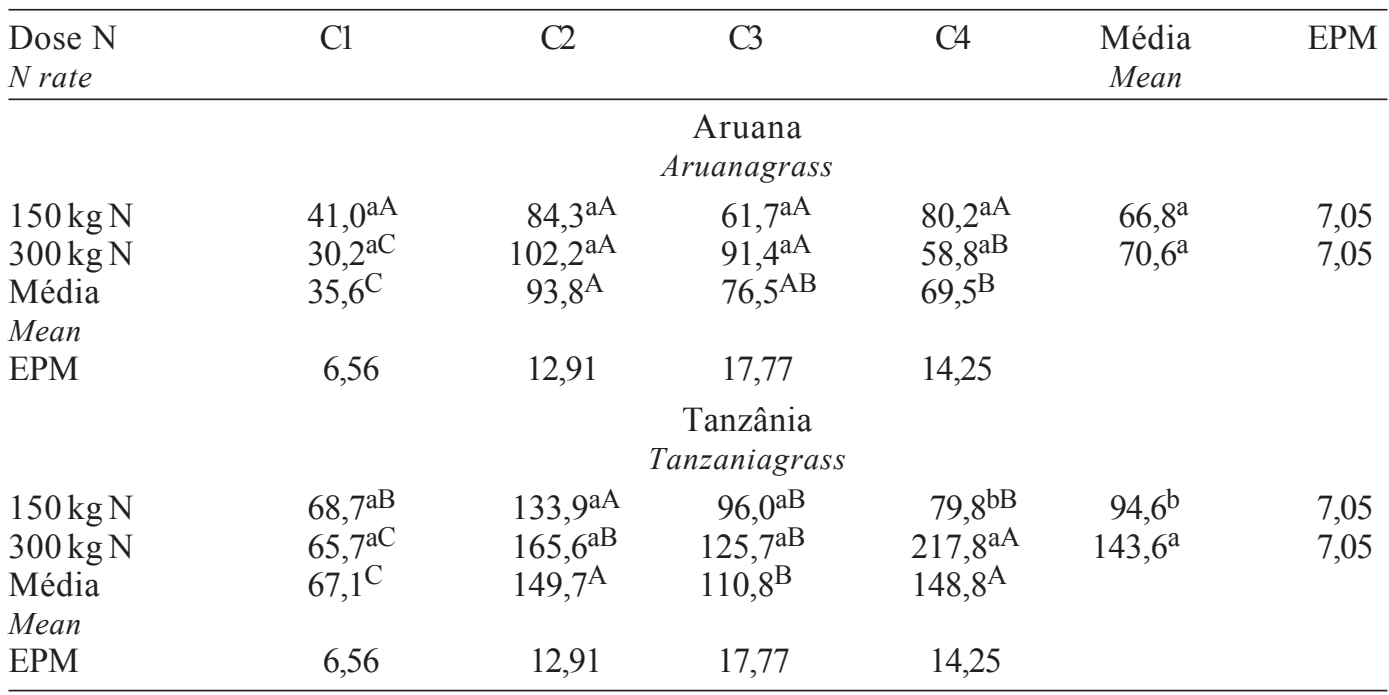

\footnotetext{
${ }^{1}$ Médias na mesma coluna seguidas da mesma letra minúscula não diferem $(p>0,10)$ entre si.

${ }^{1}$ Means in the same column followed by the same small letter do not differ $(p>0.10)$.

2 Médias na mesma linha seguidas da mesma letra maiúscula não diferem $(p>0,10)$ entre si.

2 Means in the same row followed by the same capital letter do not differ $(p>0.10)$.

3 EPM: erro-padrão da média.

${ }^{3}$ EPM: standard error of mean.

${ }^{4}$ C1 = outono; C2 = inverno; C3 = primavera; C4 = verão.

${ }^{4}$ C1 = Autumn; C2 = Winter; C3 = Spring; C4 = Summer.
}

$\mathrm{Na}$ média entre doses de $\mathrm{N}$ e ciclos de pastejo, o comprimento do sistema radicular pré-pastejo do capimtanzânia foi maior $(\mathrm{P}<0,10)\left(119,1 \mathrm{~cm} \mathrm{~cm}^{-3}\right.$ de solo) que do capim-aruana $\left(68,7 \mathrm{~cm} \mathrm{~cm}^{-3}\right.$ de solo). Na média entre capins e ciclos de pastejo, a dose de $300 \mathrm{~kg} \mathrm{ha}^{-1}$ de $\mathrm{N}$ contribuiu para maior comprimento do sistema radicular $(\mathrm{P}<0,10)\left(107,1 \mathrm{~cm} \mathrm{~cm}^{-3}\right.$ de solo) que a dose de $150 \mathrm{~kg}$ $\mathrm{ha}^{-1}$ de $\mathrm{N}\left(80,7 \mathrm{~cm} \mathrm{~cm}^{-3}\right.$ de solo). O mesmo aconteceu para a superfície do sistema radicular pré-pastejo, com o capim-tanzânia apresentando maior superfície $(\mathrm{P}<0,10)$ $\left(37,4 \mathrm{~cm}^{2} \mathrm{~cm}^{-3}\right.$ de solo) que o capim-aruana $\left(22,0 \mathrm{~cm}^{2} \mathrm{~cm}^{-3}\right.$ de solo), assim como a dose de $300 \mathrm{~kg} \mathrm{ha}^{-1}$ de $\mathrm{N}$ contribuiu para maior superfície do sistema radicular $(\mathrm{P}<0,10)\left(33,3 \mathrm{~cm}^{2} \mathrm{~cm}^{-3}\right.$ de solo $)$ que a dose de $150 \mathrm{~kg} \mathrm{ha}^{-1}$ de $\mathrm{N}\left(26,2 \mathrm{~cm}^{2} \mathrm{~cm}^{-3}\right.$ de solo).

$\mathrm{O}$ crescimento do sistema radicular nos períodos de rebrotação pós-pastejo teve sua dinâmica quantificada por meio da análise do crescimento de raízes em buracos preenchidos com areia (refilled cores), conforme Matthew (1992).

Na Figura 2, constam os resultados de crescimento de raízes quanto à massa seca da matéria orgânica 
Tabela 6 - Superfície $\left(\mathrm{cm}^{2} \mathrm{~cm}^{-3}\right.$ de solo) de raízes dos capins aruana e tanzânia, em quatro ciclos de pastejo e duas doses de $\mathrm{N}$

Table 6 - Root surface ( $\mathrm{cm}^{2} \mathrm{~cm}^{-3}$ of soil) of aruanagrass and tanzaniagrass, in four grazing cycles and two $N$ rates

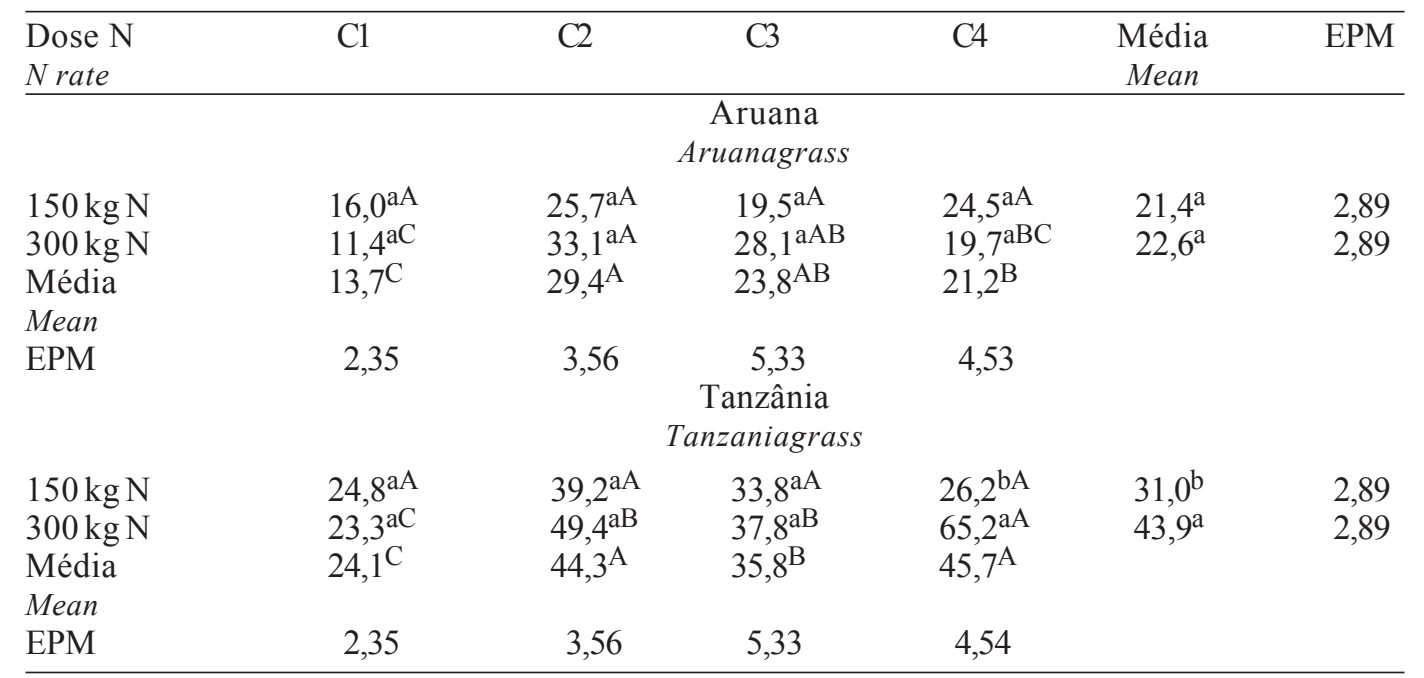

\footnotetext{
1 Médias na mesma coluna seguidas da mesma letra minúscula não diferem $(p>0,10)$ entre si.

${ }^{1}$ Means in the same column followed by the same small letter do not differ $(p>0.10)$.

2 Médias na mesma linha seguidas da mesma letra maiúscula não diferem $(p>0,10)$ entre si.

2 Means in the same row followed by the same capital letter do not differ $(p>0.10)$.

3 EPM: erro-padrão da média.

${ }^{3}$ EPM: standard error of mean.

${ }^{4} \mathrm{C} 1$ = outono; C2 = inverno; C3 = primavera; C4 = verão.

${ }^{4}$ C1 = Autumn; C2 = Winter; C3 = Spring; C4 = Summer.
}

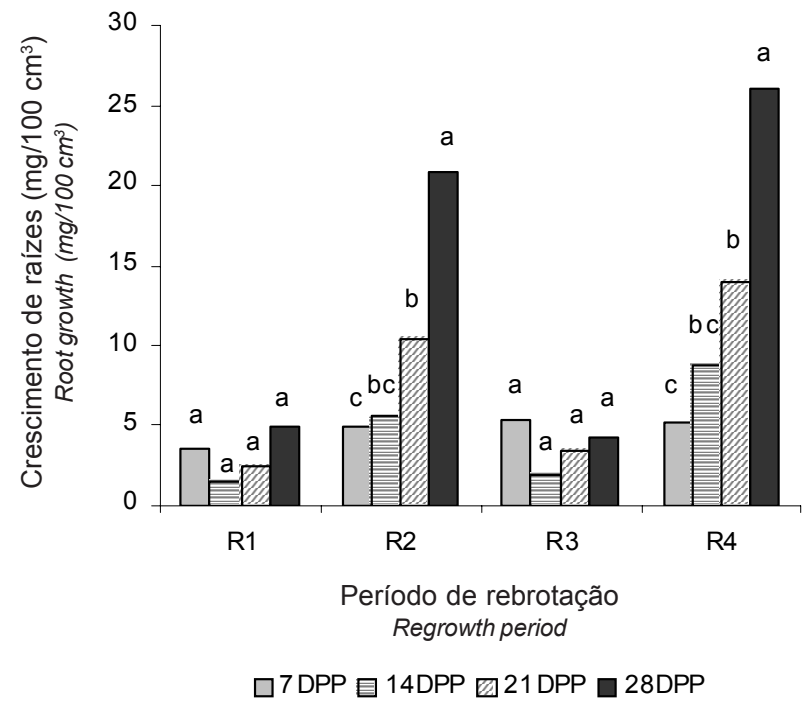

Figura 2 - Massa de raízes pós-pastejo em quatro períodos de rebrotação (R1: outono/inverno; R2: inverno; R3: primavera; R4: verão) e em quatro idades de crescimento pós-pastejo $(7,14,21$ e 28DPP: dias pós-pastejo).

Figure 2 - $\quad$ Post grazing root mass in four growing periods (R1: Autumm/Winter; R2: Winter; R3: Spring; R4: Summer) and four post grazing growing ages (7, 14, 21 and 28DPG: days post grazing).
(MSMO) (mg $\left.100 \mathrm{~cm}^{-3}\right)$, obtidos em quatro períodos de rebrotação e nas quatro idades de crescimento pós-pastejo (médias de capins e doses de N). Houve diferença entre períodos de rebrotação $(\mathrm{P}<0,10)$ e idades de crescimento pós-pastejo $(\mathrm{P}<0,10)$, assim como houve interação períodos de rebrotação $\mathrm{x}$ idades de crescimento pós-pastejo $(\mathrm{P}<0,10)$. Não foram observadas diferenças entre capins $(\mathrm{P}>0,10)$ e entre doses de $\mathrm{N}(\mathrm{P}>0,10)$ e não houve interação capins $\mathrm{x}$ doses de $\mathrm{N}$.

Os períodos em que houve maior crescimento de raízes foram o $\mathrm{R} 2 \mathrm{e} \mathrm{o} \mathrm{R} 4$, equivalentes às amostragens efetuadas nas estações de inverno e verão, ao passo que, nos períodos R1 e R3 (outono/inverno e primavera), não houve variação de crescimento de raízes $(\mathrm{P}>0,10)$. Confrontando esses dados com os de precipitação (Figura 1), percebe-se que os períodos de maior crescimento (R2 e R4) coincidem com os de maior precipitação (o mês de agosto, que coincide com o R2, foi bastante chuvoso), enquanto os dois períodos de menor crescimento (R1 e R3) correspondem às épocas de menor precipitação (o R3 ocorreu na primavera, que, nesse ano, apresentou precipitação abaixo do normal). 
Entretanto, Matthew (1992), estudando azevém perene sob pastejo na Nova Zelândia, observou que a MSMO de raízes elevou durante o período seco (verão neozelandês), ao contrário do que ocorreu no presente estudo.

Nas idades de crescimento pós-pastejo avaliadas, pode-se observar a dinâmica cronológica de desenvolvimento radicular para 7, 14, 21 e 28 dias. Nos períodos de avaliação R1 e R3, não houve diferença para MSMO de raízes $(\mathrm{P}>0,10)$ entre as idades de crescimento, coincidindo com os períodos em que houve menor crescimento do sistema radicular. Nos períodos R2 (inverno, porém com agosto chuvoso) e R4, houve diferenças para a massa de raízes $(\mathrm{P}<0,10)$ entre as idades de crescimento, sendo que, aos 7 e 14 dias, a massa de raízes foi semelhante, assim como aos 14 e 21 dias, e se acentuou dos 14 aos 28 dias pós-pastejo.

O comprimento de raízes (Figura 3 ) diferiu $(\mathrm{P}<0,10)$ nas doses de $\mathrm{N}$ e nos períodos de rebrotação, assim como houve interação $(\mathrm{P}<0,10)$ doses de $\mathrm{N}$ x períodos de rebrotação e períodos de rebrotação $\mathrm{x}$ idades de crescimento pós-pastejo. Entretanto, não foram observadas diferenças entre capins e nem interação entre capins e doses de $\mathrm{N}(\mathrm{P}>0,10)$. O crescimento
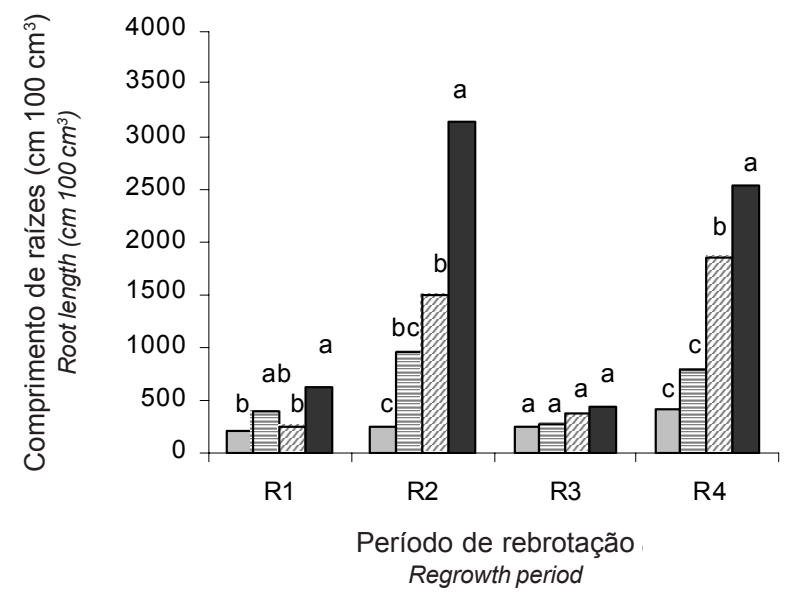

$\square$ 7DPP 目14DPP $\square$ 21DPP $\square$ 28DPP

Figura 3 - Comprimento de raízes pós-pastejo em quatro períodos de rebrotação (R1: outono/inverno; R2: inverno; R3: primavera; R4: verão) e em quatro idades de crescimento pós-pastejo (7, 14, 21 e 28 DPP: dias pós-pastejo).

Figure 3 - Post grazing root lenght in four growing periods (R1: Autumm/Winter; R2: Winter; R3: Spring; R4: Summer) and four growing ages (7, 14, 21 and 28 DPG: days post grazing). em comprimento de raízes no pós-pastejo $\left(\mathrm{cm} 100 \mathrm{~cm}^{-3}\right)$ (Figura 3) apresentou comportamento semelhante à MSMO dessas mesmas raízes (Figura 2), mostrando que ambas as variáveis podem fornecer subsídios para avaliação do comportamento do sistema radicular.

Os períodos de rebrotação em que se mensurou o maior crescimento em comprimento de raízes foram os de inverno (porém com agosto chuvoso) e verão (R2 e R4), à semelhança do que ocorreu para a variável MSMO, com a diferença de que o crescimento foi maior no período de inverno chuvoso, seguido pelo de verão. Nos períodos R1 e R3, referentes a outono/ inverno e primavera, com a limitação de chuvas, foi constatado menor crescimento do sistema radicular.

Com as idades de crescimento pós-pastejo, observou-se o crescimento, em comprimento das raízes, aos 7, 14, 21 e 28 dias. No R1, os comprimentos aos 7, 14 e 21 dias pós-pastejo não diferiram entre si $(\mathrm{P}>0,10)$, mas aos 28 dias foi maior $(\mathrm{P}<0,10)$ que aos 7 e 21 dias (Figura 3). No R3, porém, à semelhança do ocorrido com MSMO (Figura 2), as avaliações nas idades de crescimento não diferiram entre si $(\mathrm{P}>0,10)$.

Nos períodos de rebrotação R2 e R4, houve diferenças acentuadas para comprimento de raízes $(\mathrm{P}<0,10)$ entre as idades de crescimento. Para ambos os períodos de rebrotação, as avaliações aos 7 e 14 dias pós-pastejo não diferiram entre si $(\mathrm{P}>0,10)$. No $\mathrm{R} 2$, o comprimento das raízes aos 14 e 21 dias póspastejo não foi diferente $(\mathrm{P}>0,10)$, mas diferiu acentuadamente do comprimento aos 28 dias. No R4, os crescimentos em comprimento aos 7 e 14 dias póspastejo também não diferiram entre $\operatorname{si}(\mathrm{P}>0,10)$, enquanto, aos 14 dias diferiu $(\mathrm{P}<0,10)$ daquele aos 21 e 28 dias pós-pastejo, indicando que o comprimento radicular aumentou acentuadamente a partir dos 14 dias póspastejo no verão. Os compostos de reserva (carboidratos não-estruturais e compostos nitrogenados) acumulados, principalmente, na base do colmo e nas raízes das plantas (Donaghy \& Fulkerson, 1998) têm sua concentração reduzida por ocasião da desfolha, indicando que a rebrota da planta forrageira é dependente desses compostos de reserva até que a área foliar formada seja suficiente para atender as necessidades do perfilho, isto é, o perfilho em rebrota passa do estádio de dreno para fonte metabólica (Pagotto, 2001). Ao estudar o crescimento de raízes do capim-tanzânia irrigado, Pagotto (2001) afirmou que a planta fica sob condição de estresse até pelo menos duas semanas após ser colhida, independente do manejo imposto. Comportamento semelhante 
foi verificado neste experimento, podendo-se inferir que os compostos de reserva têm importante influência sobre o crescimento do sistema radicular pós-desfolha.

Constam na Figura 4 os valores de comprimento de raízes, em função das doses de $\mathrm{N}$ e períodos de rebrotação, na média dos dois capins.

No R1 e R3, não houve diferença entre as doses de $\mathrm{N}$ no comprimento das raízes $(\mathrm{P}>0,10)$. Mas nos períodos de rebrotação R2 e R4, que foram os que apresentaram maior crescimento do sistema radicular, verificou-se diferença $(\mathrm{P}<0,10)$ entre as doses de $\mathrm{N}$. A dose de $150 \mathrm{~kg} \mathrm{ha}^{-1}$ de $\mathrm{N}$ promoveu maior crescimento em comprimento do sistema radicular que a dose de $300 \mathrm{~kg} \mathrm{ha}^{-1}$ de $\mathrm{N}$.

Os resultados obtidos de crescimento em superfície do sistema radicular $\left(\mathrm{cm}^{2} 100 \mathrm{~cm}^{-3}\right)$ nos períodos de rebrotação avaliados e nas idades de crescimento pós-pastejo encontram-se na Figura 5. Houve diferença $(\mathrm{P}<0,10)$ entre doses de $\mathrm{N}$, períodos de rebrotação e idades de crescimento pós-pastejo, assim como interação $(\mathrm{P}<0,10)$ períodos de rebrotação $x$ idades de crescimento pós-pastejo. Não foram observadas diferenças entre os capins e nem interação capins $\mathrm{x}$ doses de $\mathrm{N}(\mathrm{P}>0,10)$.

Os períodos de rebrotação que apresentaram maior aumento da superfície do sistema radicular foram

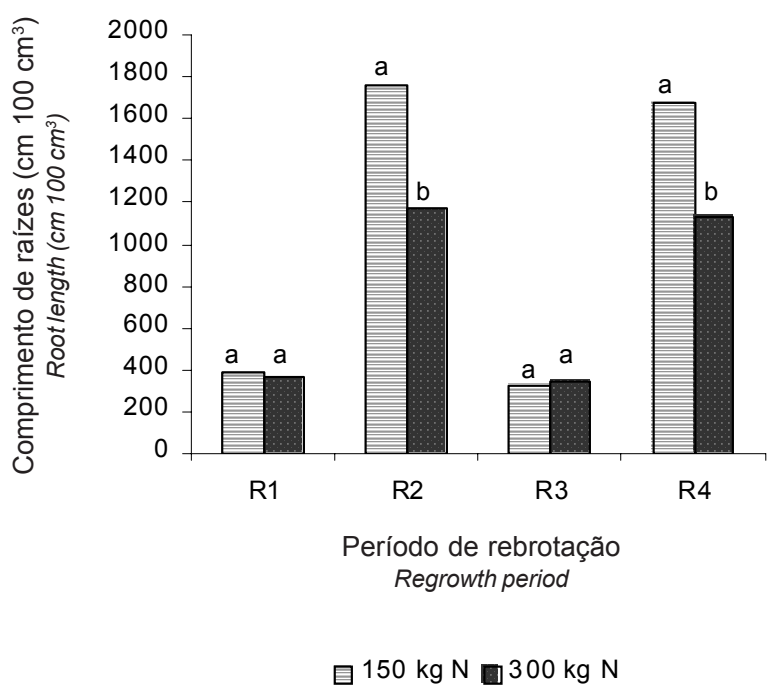

Figura 4 - Comprimento de raízes pós-pastejo em quatro períodos de rebrotação (R1: outono/inverno; R2: inverno; R3: primavera; R4: verão) e duas doses de $\mathrm{N}$ (150 e $300 \mathrm{~kg} \mathrm{ha}^{-1}$ de N).

Figure 4 - Post grazing root lenght in four regrowth periods (R1: Autumm/Winter; R2: Winter; R3: Spring; R4: Summer) and two $N$ rates (150 and $300 \mathrm{~kg} \mathrm{ha}^{-1}$ of $\mathrm{N}$ ).

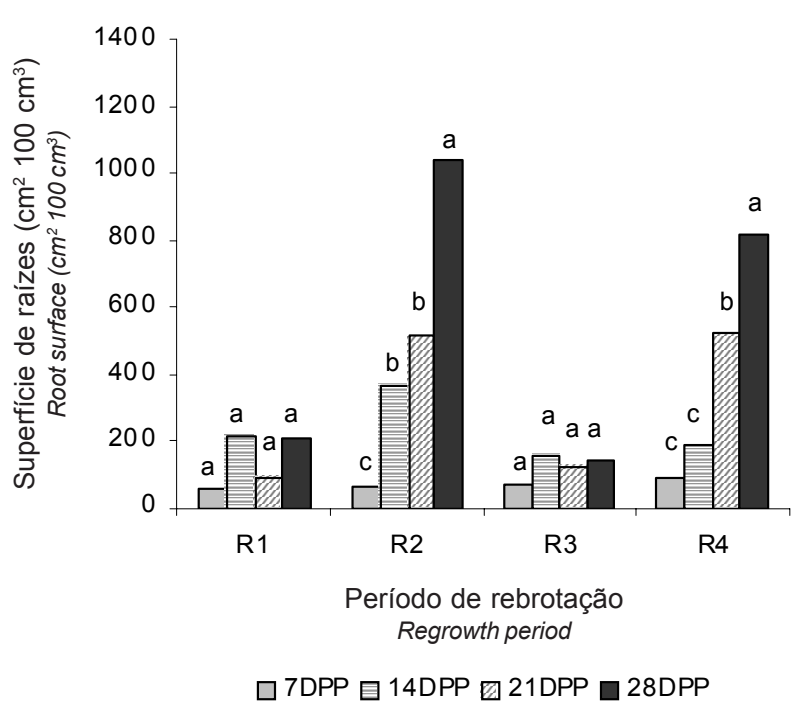

Figura 5 - Superfície de raízes pós-pastejo em quatro períodos de rebrotação (R1: outono/inverno; R2: inverno; R3: primavera; R4: verão) e em quatro idades de crescimento pós-pastejo ( 7 , 14, 21 e 28 DPP: dias pós-pastejo).

Figure 5 - Post grazing root surface in four growing periods (R1: Autumm/Winter; R2: Winter; R3: Spring; R4: Summer) and four post grazing growing ages (7, 14, 21 and 28 DPG: days post grazing).

o R2 e o R4, enquanto, nos períodos R1 e R3, não houve variação na superfície de raízes.

Nos períodos de rebrotação R1 e R3, a superfície de raízes não diferiu $(\mathrm{P}>0,10)$ entre as idades de crescimento pós-pastejo. Aos 14 dias, a superfície radicular, foi superior àquela da avaliação aos 7 dias no $\mathrm{R} 2$, mas não diferiu $(\mathrm{P}>0,10)$ no $\mathrm{R} 4$. A avaliação aos 21 dias indicou maior crescimento da superfície radicular $(\mathrm{P}<0,10)$ no $\mathrm{R} 2$ e $\mathrm{R} 4$ e crescimento também acentuado $(\mathrm{P}<0,10)$ aos 28 dias pós-pastejo.

Na Figura 6, consta o crescimento em superfície radicular em função das doses de $\mathrm{N}$ e dos períodos de rebrotação, na média dos dois capins. No R1 e R3, não houve diferença entre doses de $\mathrm{N}$ na superfície de raízes $(\mathrm{P}>0,10)$. Todavia, nos períodos de rebrotação R2 e R4, que foram os que apresentaram maior crescimento em superfície de raízes, notou-se diferença $(\mathrm{P}<0,10)$ entre as doses de $\mathrm{N}$.

Esses resultados corroboram a afirmação de Bosemark (1954) de que relação inversa entre suprimento de nitrogênio e desenvolvimento de raízes é um fenômeno bem conhecido, em que baixas doses de $\mathrm{N}$ ocasionam raízes mais longas, enquanto o aumento do suprimento de $\mathrm{N}$ resulta em raízes menores. Uma 


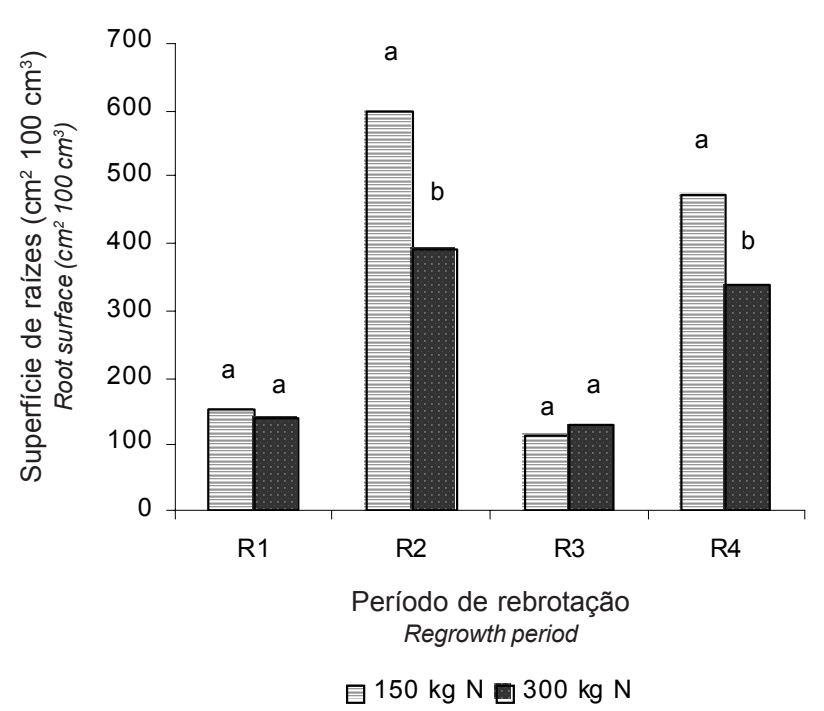

Figura 6 - Superfície de raízes pós-pastejo em quatro períodos de rebrotação (R1: outono/inverno; R2: inverno; R3: primavera; R4: verão) e duas doses de $\mathrm{N}$ (150 e $300 \mathrm{~kg} \mathrm{ha}^{-1}$ de $\mathrm{N}$ ).

Figure 6 - Post grazing root surface in four regrowth periods (R1: Autumm/Winter; R2: Winter; R3: Spring; R4: Summer) and two $\mathrm{N}$ rates (150 and $300 \mathrm{~kg} \mathrm{ha}^{-1}$ of $\mathrm{N}$ ).

possível explicação para esse comportamento, segundo Lemaire (1997), é que plantas crescendo em condições de baixa disponibilidade de $\mathrm{N}$ e, portanto, com reduzida atividade meristemática da parte aérea, alocam maior proporção de produtos da fotossíntese para o sistema radicular. Confirmando esse comportamento, Corsi et al. (2001) relatam que a estratégia da planta forrageira que rebrota em ambientes com baixa disponibilidade de $\mathrm{N}$ seria a de minimizar o impacto da desfolhação sobre o sistema radicular, uma vez que a baixa atividade meristemática nessas situações, resultado da falta de $\mathrm{N}$ no sistema, limita o rápido desenvolvimento da parte aérea e, desse modo, a retomada do balanço positivo de carbono. Portanto, o suprimento de $\mathrm{N}$ para a parte aérea depende de um sistema radicular mais desenvolvido e capaz de explorar melhor o meio edáfico. Baligar (1998), avaliando o crescimento do sistema radicular de trigo, observou que a massa de raízes foi menos afetada pela variação no suprimento de $\mathrm{N}$ que o comprimento (como neste trabalho) e que altas doses de $\mathrm{N}$ reduziram o crescimento em comprimento das raízes.

Em contrapartida, esses resultados diferem daqueles obtidos por Singh (1996), que conduziu experimento durante quatro anos para avaliar o efeito do uso de fertilizante nitrogenado em características do sistema radicular e concluiu que a aplicação de nitrogênio elevou o comprimento radicular até a dose de $200 \mathrm{~kg} \mathrm{ha}^{-1}$ de N para Panicum maximum Jacq. cv. Makueni.

$\mathrm{O}$ sistema radicular dos dois capins (Aruana e Tanzânia) seguiu padrões de crescimento semelhantes nas avaliações de MSMO, comprimento e superfície radicular. Um fator que realmente contribuiu para maior crescimento de raízes foi a ocorrência de precipitação (Tabela 7).

Durante o R1, a pluviosidade foi pequena, mas aumentou no R2, diminuiu novamente no R3, elevando-se novamente no R4. Comparando-se os dados da Tabela 7 com as Figuras 2, 3 e 5, observase que os períodos em que houve maior crescimento de raízes coincidiram com aqueles em que ocorreu maior precipitação, de modo que o maior crescimento em comprimento (Figura 3) e superfície (Figura 5) de raízes do R2 pode ser explicado pela maior precipitação. Essa hipótese é reforçada pelos resultados obtidos por Pagotto (2001), que não encontrou diferença entre épocas do ano para as variáveis massa, comprimento e superfície de raízes, provavelmente por ter trabalhado com o capimtanzânia irrigado. Além disso, esse foi um período de pouco crescimento da parte aérea, com apenas $8 \%$ do acúmulo do período avaliado (Giacomini, 2003), em que não foram utilizadas reservas para a rebrotação, que podem ser empregadas para promover maior crescimento do sistema radicular. Sheard (1973) indicou que as plantas acumulam compostos de reserva em órgãos permanentes, remanescentes após a desfolha. Conseqüentemente, órgãos como raízes, rizomas e base do colmo são utilizados para armazenálos. Lupinacci (2002), estudando reservas de carboidratos e nitrogênio no capim-marandu, encontrou maiores teores e estoques de carboidratos nãoestruturais e nitrogênio no mês de setembro. Normalmente, durante a recuperação das plantas após a desfolha, verifica-se aumento marcante na atividade de enzimas proteolíticas, com concomitante redução nos teores de proteínas solúveis presentes em órgãos de reserva, resultando na produção de aminoácidos livres, que seriam deslocados para as zonas meristemáticas e contribuiriam para formação de novos tecidos (Volenec et al., 1996), no caso, as zonas meristemáticas de raízes, pois havia pouca demanda para crescimento da parte aérea, em decorrência das condições pouco favoráveis no período. Aparente- 
Tabela 7 - Pluviosidade $(\mathrm{mm})$ e temperatura $\left({ }^{\circ} \mathrm{C}\right)$ durante os períodos de rebrotação Table 7 - Rainfall $(\mathrm{mm})$ and temperature $\left({ }^{\circ} \mathrm{C}\right)$ during the regrowth periods

\begin{tabular}{lccc}
\hline $\begin{array}{l}\text { Período } \\
\text { Period }\end{array}$ & $\begin{array}{c}\text { Data } \\
\text { Date }\end{array}$ & $\begin{array}{c}\text { Pluviosidade } \\
\text { Rainfall }\end{array}$ & $\begin{array}{c}\text { Temperatura } \\
\text { Temperature }\end{array}$ \\
\hline R1 & $30 / 05$ a $17 / 07 / 02$ & 7 & 19,1 \\
R2 & $22 / 07$ a $12 / 09 / 02$ & 101 & 20,8 \\
R3 & $11 / 09$ a $28 / 10 / 02$ & 43 & 24,5 \\
R4 & $14 / 01$ a $14 / 03 / 03$ & 251 & 25,9 \\
\hline
\end{tabular}

mente, a planta já investiu seus compostos de reserva no crescimento de raízes durante o período $\mathrm{R} 2 \mathrm{e}$, no período R3, essas reservas podem ter se esgotado.

O crescimento expressivo do sistema radicular no verão pode ter decorrido do maior crescimento da parte aérea. Como a parte aérea depende das raízes para suprimento de água e minerais, e o sistema radicular depende da parte aérea para suprimento de fotoassimilados, há uma estreita relação entre ambos os processos (Brouwer, 1962). Com o maior crescimento da parte aérea nesse período, graças às condições favoráveis de temperatura e precipitação, aumentou a necessidade de suprimento de nutrientes do solo pelo sistema radicular que, por sua vez, aumentou seu crescimento em busca desses nutrientes, tendo sido favorecido pela maior quantidade de fotoassimilados produzidos pela parte aérea. Segundo Lupinacci (2002), os menores teores e estoques de carboidratos não-estruturais e nitrogênio foram encontrados nos meses de janeiro e fevereiro, o que significa pouco investimento em acúmulo de reservas, pois os fotoassimilados estavam sendo utilizados para crescimento da parte aérea e do sistema radicular.

O crescimento radicular é lento após o pastejo, mas crescente com o aumento das idades de avaliação. Resultados semelhantes foram encontrados por Donaghy \& Fulkerson (1998), que constataram que plantas de azevém perene cessavam o crescimento radicular após desfolhação, refazendo nova área foliar (rebrotação) e retomando seu crescimento a seguir. Também Pagotto (2001), com capimtanzânia irrigado, verificou que não houve crescimento radicular nos três primeiros dias pós-pastejo, tendo este sido mais intenso entre 12 e 30 dias póspastejo, nas condições de seu experimento (diferentes resíduos pós-pastejo e irrigação).

\section{Conclusões}

Um fator que teve grande influência no crescimento do sistema radicular foi a pluviosidade. No entanto, mais estudos devem ser realizados acerca da atividade de raízes para se conhecer o significado efetivo desse comportamento e quais as relações com a perenidade da planta forrageira no sistema de produção.

A adubação nitrogenada influenciou no crescimento de raízes nos períodos em que houve maior pluviosidade, de modo que a menor dose de N promoveu maior crescimento de raízes.

\section{Literatura Citada}

BALIGAR, V.C.; FAGERIA, N.K. ELRASHIDI, M.A. Toxitity and nutrient constraints on root growth. Hort Science, v.33, n.6, p.960-965, 1998.

BONO, J.A.; MACEDO, M.C.M.; EUCLIDES, V.B.P. Biomassa e área do sistema radicular e resistência do solo à penetração em pastagens de Panicum maximum Jacq. sob pastejo rotacionado. In: REUNIÃO ANUAL DA SOCIEDADE BRASILEIRA DE ZOOTECNIA, 37., 2000, Viçosa, MG. Anais.. Viçosa, MG: SBZ, 2000. CD-ROM. Forragicultura.

BOSEMARK, N.O. The influence of nitrogen on root development. Physiologia Plantarum, v.7, p.497-502, 1954.

BOUMA, T.J.; NIELSEN, K.L.; KOUTSTAAL, B. Sample preparation and scanning protocol for computerised analysis of root length and diameter. Plant and Soil, v.218, p.185-196, 2000.

BROUWER, R. Nutritive influences on the distribution of dry matter in the plant. Netherlands Journal of Agricultural Science, v.10, n.5, p.399-408, 1962.

CARVALHO, M.C.S. Práticas de recuperação de uma pastagem degradada e seus impactos em atributos físicos, químicos e microbiológicos do solo. Piracicaba: Escola Superior de Agricultura Luiz de Queiroz, 1999. 103p. Tese (Doutorado em Agronomia) - Escola Superior de Agricultura Luiz de Queiroz, 1999.

CARVALHO, D.D.; PAGANO, A.A.G.; FIGUEIRAS, J.F. et al. Cobertura de solo e tamanho de touceiras em pastagens de capins aruana e tanzânia. In: REUNIÃO ANUAL DA SOCIEDADE BRASILEIRA DE ZOOTECNIA, 40., Santa Maria. Anais... Santa Maria: Sociedade Brasileira de Zootecnia, 2003. CD-ROM. Forragicultura.

CECATO, U.; HERLING, V.R.; BRAGA, L.M. et al. Carboidratos, nitrogênio total e peso de raízes em capim-tanzânia (Panicum maximum Jacq, cv. Tanzânia) adubado com diferentes doses de nitrogênio sob pastejo. In: REUNIÃO ANUAL DA SOCIEDADE BRASILEIRA DE ZOOTECNIA, 40., Santa Maria. Anais... Santa Maria: Sociedade Brasileira de Zootecnia, 2003. CD-ROM. Forragicultura. 
CORSI, M.; MARTHA JR., G.B.; PAGOTTO, D.S. Sistema radicular: dinâmica e resposta a regimes de desfolha. In: MATTOS, W.R.S. (Ed.) A produção animal na visão dos brasileiros. Piracicaba: Sociedade Brasileira de Zootecnia, 2001. p.838-852.

DA COSTA, N.A.; CORSI, M.; DE FARIA, V.P. Efeito da altura e intervalo de cortes sobre a produção de massa seca aérea e peso da matéria orgânica do sistema radicular do capimandropogon (Andropogon gayanus, Kunth). O Solo, v.75, n.2, p.5-10, 1983.

DEINUM, B. Root mass of swards in different grazing systems. Netherlands Journal of Agricultural Science, v.33, p.377-384, 1985.

DONAGHY, D.J.; FULKERSON, W.J. Priority for allocation of water soluble carbohydrate reserves during regrowth of Lollium perenne. Grass and Forage Science, v.53, p.211-218, 1998.

EMPRESA BRASILEIRA DE PESQUISA AGROPECUÁRIA EMBRAPA. Sistema brasileiro de classificação de solos. Serviço Nacional de Levantamento e Conservação de Solos. Brasília: EMBRAPA, 1999, 412p.

GIACOMINI, A.A. Produção de forragem, massa e crescimento de raízes dos capins Aruana e Tanzânia submetidos a doses de nitrogênio, em lotação rotacionada com ovinos. Piracicaba: Escola Superior de Agricultura Luiz de Queiroz, 2003.66p. Dissertação (Mestrado em Agronomia) - Escola Superior de Agricultura Luiz de Queiroz, 2003.

GREENWOOD, K.K.; HUTCHINSON, K.J. Root characteristics of temperate pasture in New South Wales after grazing at three stocking rates for 30 years. Grass and Forage Science, v.53, p.120-128, 1998

HERLING, V.R.; RODRIGUES, L.R.A.; LUZ, P.H.C. Manejo do pastejo. In: SIMPÓSIO SOBRE MANEJO DA PASTAGEM: planejamento e sistemas de produção em pastagens. 18., Piracicaba. Anais... Piracicaba: Fundação de Estudos Agrários Luiz de Queiroz, 2001. p.157-192.

LEMAIRE, G. The physiology of grass growth under grazing: tissue turn-over. In: SIMPÓSIO INTERNACIONAL SOBRE PRODUÇÃO ANIMAL EM PASTEJO, 1997, Viçosa, MG. Anais... Viçosa, MG: Universidade Federal de Viçosa, 1997. p.117-144.

LUPINACCI, Reservas orgânicas, índice de área foliar e produção de forragem em Brachiaria brizantha cv. Marandu submetida a intensidades de pastejo por bovinos de corte. Piracicaba: Fundação de Estudos Agrários Luiz de Queiroz, 2002. 150p. Dissertação (Mestrado em Agronomia) - Escola Superior de Agricultura "Luiz de Queiroz", 2002.

MATTA, F.M. In: WORKSHOP SOBRE SISTEMA RADICULAR: metodologias e estudo de casos. Aracaju. Anais... Aracaju: EMBRAPA Tabuleiros Costeiros, 1999. $300 \mathrm{p}$.

MATTHEW, C. A study of seasonal root and tiller dinamics in swards of perennial ryegrass (Lolium perenne, $\mathrm{L}$ ). Palmerston North: Thesis (Ph.D.). Massey University, 1992.
PAGOTTO, D.S. Comportamento do sistema radicular do capim-tanzânia (Panicum maximum Jacq.) sob irrigação e submetido a diferentes intensidades de pastejo. Piracicaba: Fundação de Estudos Agrários Luiz de Queiroz, 2001. 51p. Dissertação (Mestrado em Agronomia) - Escola Superior de Agricultura “Luiz de Queiroz", Universidade de São Paulo, 2001.

RICHARDS, J.H. Physiology of plant recovery from defoliation. In: BAKER, M.J. (Ed). Grassland for our world. Wellington: SIR Publishing, 1993. p.46-54.

SANTOS, L.E.; CUNHA, E.A.; BUENO, M.S. Altas lotações nas pastagens: uma técnica viável para ovinos. Nova Odessa, Instituto de Zootecnia, 2001. 45p.

SAS INSTITUTE Property software release 8. Cary, NC: SAS Institute Inc., 1999. 956p.

SCURLOCK, J.M.O.; HALL, D.O. The global carbon sink: a grassland perspective. Global Change Biology, v.4, p.229-233, 1998.

SHEARD, R.W. Organic reserves and plant regrowth. In: BUTLER, G.W.; BAIleY, R.W. (Eds.). Chemistry and biochemistry of herbage. London: Academic Press, 1973. p.353-377.

SINGH, K.A. Effect of age, cutting interval, nitrogen and farmyard manure on root growth parameters of forage grasses in na acid Inceptisol. Indian Journal of Agricultural Sciences, v.66, n.1, p.38-44, 1996.

SINGH, B.P. Soil environment and root growth: Introduction to the colloquium. Hort Science, v.33, n.6, p.946-947, 1998.

TOSI, P. Estabelecimento de parâmetros agronômicos para o manejo e eficiência de utilização de Panicum maximum Jacq. cv. Tanzânia-1 sob pastejo rotacionado. Piracicaba: Fundação de Estudos Agrários Luiz de Queiroz, 1999. 103p. Dissertação (Mestrado) - Escola Superior de Agricultura "Luiz de Queiroz", Universidade de São Paulo, 1999.

VOGT, K.A.; BLOOMFIELD, J. Tree root turnover and senescence. In: WAISEL, Y.; ESHEL, A.; KAFKAFI, U. (Eds.) Plant roots: the hidden half. New York: Marcel Dekker, 1991. p.287-308.

VOLENCEC, J.J.; OURRY, A.; JOERN, B.C. A role for nitrogen reserves in forage regrowth and stress tolerance. Physiologia Plantarum, v.97, p.5-193, 1996.

VOORHEES, W.B.; CARLSON, V.A.; HALLAUER, E.A. Root lenght measurement with a computer-controlled digital scanning microdensitometer. Agronomy Journal, v.72, p.847-850, 1980.

WERNER, J.C.; COLOZZA, M.T.; MONTEIRO, F.A. Adubação de Pastagens. In: SIMPÓSIO SOBRE MANEJO DA PASTAGEM - Planejamento de Sistemas de Produção em Pastagens, 18., 2001, Piracicaba. Anais... Piracicaba: Fundação de Estudos Agrários Luiz de Queiroz, 2001. p.129-156.

Recebido em: 29/03/04 Aceito em: 17/11/04 